\title{
Efficacy of tamoxifen \pm aminoglutethimide in normal weight and overweight postmenopausal patients with hormone receptor-positive breast cancer: an analysis of 1509 patients of the ABCSG-06 trial
}

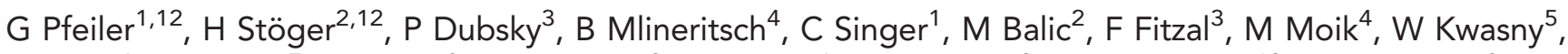
U Selim ${ }^{6}$, K Renner ${ }^{7}$, F Ploner ${ }^{2}$, G G Steger ${ }^{8}$, M Seifert ${ }^{1}$, F Hofbauer ${ }^{9}$, P Sandbichler ${ }^{10}$, H Samonigg ${ }^{2}$, R Jakesz ${ }^{3}$, R Greil $^{4}, C$ Fesl $^{11}$ and M Gnant ${ }^{\star}, 3$ on behalf of the ABCSG

${ }^{1}$ Division of Gynecology and Gynecological Oncology, Department of Obstetrics and Gynecology, Comprehensive Cancer Center Vienna, Medical University of Vienna, Vienna, Austria; ${ }^{2}$ Department of Medical Oncology, Medical University of Graz, Graz, Austria; ${ }^{3}$ Department of Surgery, Comprehensive Cancer Center Vienna, Medical University of Vienna, Vienna, Austria; ${ }^{4}$ IIrrd Medical Department with Hematology and Medical Oncology, Hemostaeology, Infectious Disease and Rheumatology, Onoclogy Center, Paracelus Medical University Hospital Salzburg, Salzburg, Austria; ${ }^{5}$ Department of Surgery, Wiener Neustadt Hospital, Wiener Neustadt, Austria; ${ }^{6}$ Department of Surgery, Hanusch Medical Center, Vienna, Austria; ${ }^{7}$ Department of Surgery, Sozialmedizinisches Zentrum Ost, Vienna, Austria; ${ }^{8}$ Division of Oncology, Department of Internal Medicine I, Medical University of Vienna, Vienna, Austria; ${ }^{9}$ Department of Surgery, Oberpullendorf Hospital, Oberpullendorf, Austria; ${ }^{10}$ Department of Surgery, St Vinzenz Hospital, Zams, Austria and ${ }^{11}$ Austrian Breast and Colorectal Cancer Study Group, Vienna, Austria

Background: There exists evidence that body mass index (BMI) impacts on the efficacy of aromatase inhibitors in patients with breast cancer. The relationship between $\mathrm{BMI}$ and the efficacy of tamoxifen is conflicting. We investigated the impact of BMl on the efficacy of single tamoxifen and tamoxifen plus an aromatase inhibitor in the well-defined prospective study population of the ABCSG-06 trial.

Methods: ABCSG-06 investigated the efficacy of tamoxifen vs tamoxifen plus aminoglutethimide in postmenopausal women with hormone receptor-positive breast cancer. Taking BMI at baseline, patients were classified as normal weight $(\mathrm{BMI}=$ $\left.18.5-24.9 \mathrm{~kg} \mathrm{~m}^{-2}\right)$, overweight $\left(\mathrm{BMI}=25-29.9 \mathrm{~kg} \mathrm{~m}^{-2}\right)$, and obese $\left(30 \mathrm{~kg} \mathrm{~m}^{-2}\right)$ according to WHO criteria.

Results: Overweight + obese patients had an increased risk for distant recurrences (hazard ratio (HR): 1.51; Cox $P=0 \cdot 018$ ) and a worse overall survival (OS; HR: 1 49; Cox $P=0$. 052) compared with normal weight patients. Analysing patients treated with single tamoxifen only, no difference between overweight + obese patients and normal weight patients regarding distant recurrence-free survival (HR: 1.35; Cox $P=0.24)$ and OS (HR: 0.99; Cox $P=0.97)$ could be observed. In contrast, in the group of patients treated with the combination of tamoxifen plus aminoglutethimide, overweight + obese patients had an increased risk for distant recurrences (1.67; Cox $P=0.03)$ and a worse OS (1.47; Cox $P=0$.11) compared with normal weight patients.

Conclusion: BMI impacts on the efficacy of aromatase inhibitor-based treatment but not single tamoxifen.

*Correspondence: Professor M Gnant; E-mail: michael.gnant@meduniwien.ac.at

Presented in part at the San Antonio Breast Cancer Symposium 2010-Obesity and Breast Cancer (Poster Discussion Session).

${ }^{12}$ These authors contributed equally to this work.

Received 6 December 2012; revised 15 February 2013; accepted 20 February 2013; published online 19 March 2013

(c) 2013 Cancer Research UK. All rights reserved 0007-0920/13 
Obesity is an increasing health-economic problem. In developed countries like the United States, up to two-thirds of the population above the age of 18 years are overweight (body mass index (BMI) of 25-29.9 $\mathrm{kg} \mathrm{m}^{-2}$ ) or obese (BMI $\geqslant 30 \mathrm{~kg} \mathrm{~m}^{-2}$; Felgal et al, 2010). Increased BMI impacts on the development of certain diseases like type 2 diabetes, hypertension, coronary heart disease, stroke, and cancer (Després and Lemieux 2006; Renehan et al, 2008).

With respect to breast cancer, BMI is not only an established independent risk factor in postmenopausal women, but also impacts on disease outcome in pre- and postmenopausal patients (de Azambuja et al, 2010; Parr et al, 2010; Protani et al, 2010). Recently, Ewertz et al (2011) demonstrated that overweight and obese patients with breast cancer are at increased risk for distant metastases and breast cancer-related death compared with normal weight patients. Several mechanisms including increased estrogen serum levels in overweight postmenopausal women might be responsible for this prognostic impact of BMI. Elevated estrogen serum levels in overweight postmenopausal women are a consequence of increased aromatisation of androgens to estrogens in fat tissue (Longcope et al, 1986; Key et al, 2003). Increased estrogen serum levels can stimulate cancer cells, which may lead to disease recurrence and thereby impact on disease outcome.

However, obesity and consequently elevated estrogen serum levels could also impact on the efficacy of endocrine therapy. Tamoxifen has been a standard adjuvant endocrine treatment in premenopausal patients with breast cancer since more than 3 decades, and is still in wide-spread use in postmenopausal patients worldwide. It competitively inhibits the estrogen receptor and thereby estrogenic stimulation of tumour cells. Retrospective analyses of several trials indicate that there exists no impact of BMI on the efficacy of tamoxifen (Dignam et al, 2003; Sestak et al, 2010; Pfeiler et al, 2011). However, recent data of the TEAM trial demonstrated a worse outcome of obese patients treated with tamoxifen (Seynaeve et al, 2011). Therefore, this issue remains unclear and more data are needed to draw conclusions.

Aromatase inhibitors target the enzyme aromatase to lower estrogen serum levels in postmenopausal women. As the enzyme aromatase is more abundant in overweight women, it has been hypothesised that standard dosages of aromatase inhibitors are not able to equally suppress estrogen serum levels in overweight and normal weight patients, which might affect disease outcome. In fact, recent literature indicates that BMI significantly impacts on the efficacy of aromatase inhibitors in gonadotropin-releasing hormone-treated premenopausal and in postmenopausal patients with breast cancer (Pfeiler et al, 2011; Seynaeve et al, 2011).

The ABCSG-06 trial compared the efficacy of tamoxifen and tamoxifen plus aminoglutethimide - a first generation aromatase inhibitor -in postmenopausal patients with hormone receptorpositive breast cancer (Schmid et al, 2003). Adding aminoglutethimide to the first 2 years of 5 years of tamoxifen did not improve outcome compared with tamoxifen alone. However, a subgroup analysis indicated that patients with G3 tumours experienced significant benefit from the combination therapy compared with tamoxifen alone.

To further elucidate the prognostic and predictive value of BMI in breast cancer, we investigated disease outcome and efficacy of single tamoxifen and tamoxifen plus a first generation aromatase inhibitor in dependence of BMI in the well-defined prospective study population of the ABCSG-06 trial. This is the first report on the impact of BMI on the combination endocrine therapy of tamoxifen plus an aromatase inhibitor.

\section{MATERIALS AND METHODS}

Between 1990 and 1995, the prospective randomised controlled ABCSG-06 trial (NCT 00309491) recruited 2020 postmenopausal patients with breast cancer, who were randomly assigned to receive either tamoxifen alone for 5 years or tamoxifen for 5 years in combination with aminoglutethimide for the first 2 years (Schmid et al, 2003). The dosage of tamoxifen was $40 \mathrm{mg}$ daily for the first 2 years and $20 \mathrm{mg}$ daily for the following 3 years in both arms. An increased dosage of tamoxifen was chosen for the first 2 years, as there exists evidence that the simultaneously given aromatase inhibitor may reduce bioavailability of tamoxifen (Lien et al, 1990). All patients included in this trial were estrogen and/or progesterone receptor positive, which was confirmed either by biochemical or immunohistochemical analyses. Breast cancer patients with stage I or stage II disease were included. The primary end point of this trial was overall survival (OS), which was defined as the number of months from the date of randomisation until death. Secondary end points were disease-free survival (DFS) - including locoregional, distant, or combined recurrences, contralateral or secondary carcinoma as well as death from any cause -and side effects of the treatment. Details of the protocol have been reported in a previous publication (Schmid et al, 2003). This study has been approved by regulatory and ethics committees for all participating centres. Written informed consent was signed by all participating patients. In this retrospecitve analysis, we investigated the prognositc and predictive impact of BMI on the secondary end points (DFS, safety, and additionally distant recurrence-free survival) and on the primary end point (OS).

For this analysis, weight and height at baseline were used for calculation of BMI. Patients were grouped according to the established WHO criteria in underweight (BMI $<18.5 \mathrm{~kg} \mathrm{~m}^{-2}$ ), normal weight (BMI of $18.5-24.9 \mathrm{~kg} \mathrm{~m}^{-2}$ ), overweight (BMI of $25-29.9 \mathrm{~kg} \mathrm{~m}^{-2}$ ), and obese patients (BMI > $30 \mathrm{~kg} \mathrm{~m}^{-2}$; WHO, 1995). Patients without available information of height, weight, or both were excluded from this analysis. For this analysis, distant recurrence-free survival included distant metastases only but not death.

Statistical analyses. The data were retrospectively analysed for primary and secondary end points according to the BMI subgroups as well as the two treatment arms. Because many relapse-free patients were re-randomised to the ABCSG-6a trial (investigating extended adjuvant therapy - additional 3 years of anastrozole $v s$ nihil [NCT00300508]), all patients in this analysis were censored

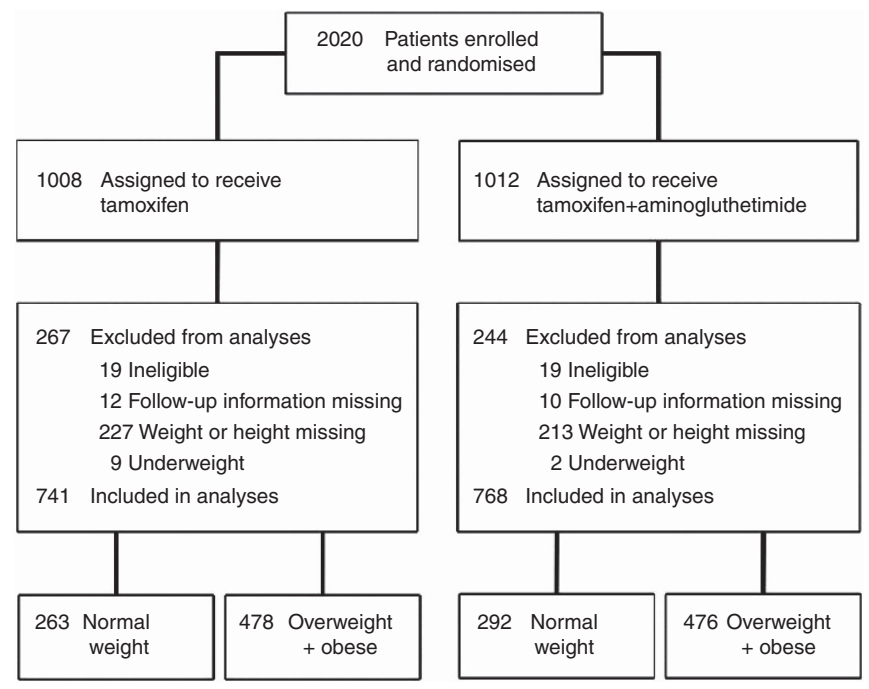

Figure 1. Consort diagram. 
Table 1. Patient demographics and tumour characteristics

\begin{tabular}{|c|c|c|c|c|c|c|c|c|c|c|}
\hline \multirow[b]{2}{*}{ Characteristics } & \multicolumn{5}{|c|}{ Normal weight } & \multicolumn{5}{|c|}{ Overweight + obese } \\
\hline & \multicolumn{2}{|c|}{ Tamoxifen } & \multicolumn{2}{|c|}{$\begin{array}{c}\text { Tamoxifen }+ \\
\text { aminoglutethimide }\end{array}$} & $\boldsymbol{P}$-value & \multicolumn{2}{|c|}{ Tamoxifen } & \multicolumn{2}{|c|}{\begin{tabular}{|c|} 
Tamoxifen + \\
aminoglutethimide
\end{tabular}} & $\boldsymbol{P}$-value \\
\hline No. of patients & \multicolumn{2}{|c|}{263} & \multicolumn{2}{|c|}{292} & & \multicolumn{2}{|c|}{478} & \multicolumn{2}{|c|}{476} & \\
\hline Percentage (\%) & \multicolumn{2}{|c|}{35} & \multicolumn{2}{|c|}{38} & & \multicolumn{2}{|c|}{65} & \multicolumn{2}{|c|}{62} & \\
\hline \multicolumn{11}{|l|}{ Body mass index } \\
\hline Median & \multicolumn{2}{|c|}{23.4} & \multicolumn{2}{|c|}{23.2} & 0.741 & \multicolumn{2}{|c|}{28.6} & \multicolumn{2}{|c|}{28.2} & 0.310 \\
\hline Range & 19.0 & 25.0 & 19.0 & 25.0 & & 25.0 & 46.5 & 25.0 & 46.9 & \\
\hline \multicolumn{11}{|l|}{ Age (years) } \\
\hline Median & \multicolumn{2}{|c|}{64} & \multicolumn{2}{|c|}{62} & 0.376 & \multicolumn{2}{|c|}{64} & & & 0.151 \\
\hline Range & 47 & 80 & 41 & 79 & & 43 & 80 & 46 & 79 & \\
\hline & $n$ & $\%$ & $n$ & $\%$ & & $n$ & $\%$ & $n$ & $\%$ & \\
\hline Type of surgery & & & & & & & & & & \\
\hline Breast retaining & 140 & 53.2 & 155 & 53.1 & 0.972 & 244 & 51.0 & 237 & 49.8 & 0.698 \\
\hline Radically modified & 123 & 46.8 & 137 & 46.9 & & 234 & 49.0 & 239 & 50.2 & \\
\hline Cancer stage & & & & & & & & & & \\
\hline pT1 & 149 & 56.7 & 182 & 62.3 & 0.110 & 263 & 55.0 & 243 & 51.0 & 0.348 \\
\hline рT2 & 101 & 38.4 & 104 & 35.6 & & 204 & 42.7 & 217 & 45.6 & \\
\hline pT3 & 13 & 4.9 & 6 & 2.1 & & 11 & 2.3 & 16 & 3.4 & \\
\hline Nodal status & & & & & & & & & & \\
\hline pNO & 165 & 62.7 & 178 & 61.0 & 0.828 & 279 & 58.4 & 283 & 59.5 & 0.939 \\
\hline pN1 & 68 & 25.9 & 85 & 29.1 & & 125 & 26.1 & 124 & 26.0 & \\
\hline pN2 & 23 & 8.7 & 22 & 7.5 & & 54 & 11.3 & 48 & 10.1 & \\
\hline pN3 & 7 & 2.7 & 7 & 2.4 & & 20 & 4.2 & 21 & 4.4 & \\
\hline Tumour grading & & & & & & & & & & \\
\hline G1 & 36 & 13.7 & 44 & 15.1 & 0.440 & 72 & 15.1 & 72 & 15.1 & 0.725 \\
\hline G2 & 153 & 58.2 & 155 & 53.1 & & 279 & 58.4 & 263 & 55.3 & \\
\hline G3 & 61 & 23.2 & 70 & 23.9 & & 103 & 21.5 & 112 & 23.5 & \\
\hline Gx & 13 & 4.9 & 23 & 7.9 & & 24 & 5.0 & 29 & 6.1 & \\
\hline Estrogen receptor stat & & & & & & & & & & \\
\hline Negative $(-)$ & 8 & 3.0 & 8 & 2.7 & 0.573 & 7 & 1.5 & 14 & 2.9 & 0.461 \\
\hline Low expression $(+)$ & 46 & 17.5 & 49 & 16.8 & & 78 & 16.3 & 68 & 14.3 & \\
\hline Medium expression $(++)$ & 87 & 33.1 & 83 & 28.4 & & 181 & 37.9 & 168 & 35.3 & \\
\hline High expression $(+++)$ & 79 & 30.0 & 89 & 30.5 & & 131 & 27.4 & 143 & 30.0 & \\
\hline Unknown & 43 & 16.4 & 63 & 21.6 & & 81 & 16.9 & 83 & 17.5 & \\
\hline Progesterone receptor & & & & & & & & & & \\
\hline Negative (-) & 42 & 16.0 & 47 & 16.1 & 0.603 & 75 & 15.7 & 77 & 16.2 & 0.738 \\
\hline Low expression $(+)$ & 48 & 18.3 & 55 & 18.8 & & 95 & 19.9 & 80 & 16.8 & \\
\hline Medium expression $(++)$ & 79 & 30.0 & 72 & 24.7 & & 123 & 25.7 & 119 & 25.0 & \\
\hline High expression $(+++)$ & 49 & 18.6 & 55 & 18.8 & & 104 & 21.8 & 117 & 24.6 & \\
\hline Unknown & 45 & 17.1 & 63 & 21.6 & & 81 & 16.9 & 83 & 17.4 & \\
\hline
\end{tabular}

after 60 months to avoid bias due to different therapies. Groups were compared by using a Cox proportional hazards regression model and the log-rank test was used for DFS, distant recurrencefree survival, and OS. Kaplan-Meier plots for DFS, distant recurrence-free survival, and OS were used for each comparison. A multivariate Cox regression model with adjustment for treatment, tumour stage, nodal stage, grade, ER, PR, and age was performed for the comparison of overweight/obese vs normal weight patients with regard to DFS, distant recurrence-free survival, and OS. Fisher's Exact test and Kruskal-Wallis test, respectively, were used for comparison of demographic data and side effects. All $P$-values are two sided and a value of $<0.05$ was considered statistically significant.

\section{RESULTS}

The ABCSG-06 trial enrolled 2020 postmenopausal patients with hormone receptor-positive early breast cancer. Complete patient 
Table 2. Events of normal weight and overweight + obese patients treated with tamoxifen vs tamoxifen plus amingluthetimide

\begin{tabular}{|c|c|c|c|c|c|c|c|c|}
\hline & \multicolumn{4}{|c|}{ Normal weight } & \multicolumn{4}{|c|}{ Overweight + obese } \\
\hline & \multicolumn{2}{|c|}{ Tamxoifen } & \multicolumn{2}{|c|}{$\begin{array}{c}\text { Tamoxifen }+ \\
\text { aminoglutethimide }\end{array}$} & \multicolumn{2}{|c|}{ Tamoxifen } & \multicolumn{2}{|c|}{$\begin{array}{c}\text { Tamoxifen }+ \\
\text { aminoglutethimide }\end{array}$} \\
\hline & $\mathbf{N}$ & $\%$ & $\mathbf{N}$ & $\%$ & $\mathbf{N}$ & $\%$ & $\mathbf{N}$ & $\%$ \\
\hline Number of patients & 263 & & 292 & & 478 & & 476 & \\
\hline All events & 67 & 25.5 & 76 & 26.0 & 143 & 30.5 & 145 & 28.6 \\
\hline Locoregional & 9 & 3.4 & 14 & 4.8 & 13 & 2.7 & 7 & 1.5 \\
\hline Distant & 22 & 8.4 & 24 & 8.2 & 54 & 11.3 & 62 & 13.0 \\
\hline Contralateral & 3 & 1.1 & 2 & 0.7 & 6 & 1.3 & 9 & 1.9 \\
\hline Secondary malignant conditions & 5 & 1.9 & 11 & 3.8 & 19 & 4.0 & 9 & 1.9 \\
\hline Death & 28 & 10.6 & 25 & 8.6 & 51 & 10.7 & 58 & 12.2 \\
\hline
\end{tabular}

Distant recurrence free

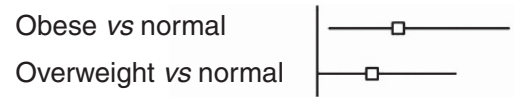

Overall survival

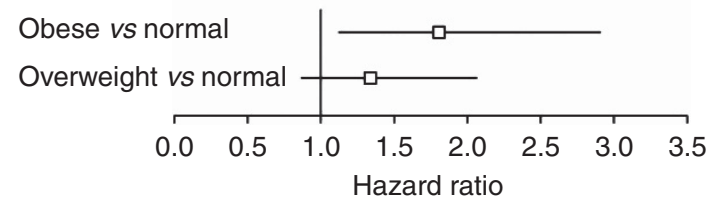

Figure 2. Hazard plots for overweight and obese vs normal weight patients for distant recurrence-free survival and overall survival. $\mathrm{HR}=$ hazard ratio.

data information including weight and height was available in 1520 patients $(75 \%)$. Eleven underweight patients $(0.7 \%$; nine patients of the tamoxifen arm and two patients of the tamoxifen + aminogluthetimide arm) were excluded due to small numbers and for biological reasons. Therefore, 1509 patients (741 patients of the tamoxifen arm and 768 patients of the tamoxifen + aminoglutethimide arm) were included in further analyses (Figure 1).

Of these patients, one-third (555 patients, 37\%) were normal weight and two-third were overweight (639 patients, $42 \%$ ) or obese (315 patients, 21\%). Patient demographics and tumour characteristics of both treatment arms according to BMI (normal weight $v s$ overweight + obese) are shown in Table 1. Patient demographics and tumour characteristics of the four groups were well balanced.

Efficacy: outcome according to BMI. This analysis reports on a median follow-up of 60 months. During the observation period, 431 events including 162 deaths occurred; 61 deaths were not breast cancer related (Table 2).

Evaluation of the impact of BMI on DFS demonstrated no difference between normal weight and overweight + obese patients (hazard ratio (HR): $1.11 ; 95 \%$ confidence interval (CI): 0.88-1.41, Cox $P=0.38$ ). A multivariate Cox regression model, which adjusted for treatment, tumour stage, nodal stage, tumour grade, $\mathrm{ER}, \mathrm{PR}$, and age, indicated a nonsignificant numerically worse DFS of the overweight + obese patient group (HR: 1.25; 95\% CI: $0.95-1.64, P=0.11)$. Overweight + obese patients had a significant 1.5 -fold increased risk to develop distant metastases compared with normal weight patients (HR: 1.51 ; 95\% CI: $1.07-2.13$, Cox
$P=0.018)$. A simultaneous comparison between obese, overweight, and normal weight patients demonstrated a significant increased risk for distant recurrences for obese (HR: 1.62; 95\% CI: 1.06-2.47, Cox $P=0.02$ ) and overweight patients (HR: $1.46 ; 95 \% \mathrm{CI}$ : 1.01-2.10, Cox $P=0.04$ ) compared with normal weight patients (Figure 2).

Regarding OS, no difference between overweight + obese patients compared with normal weight patients was observed in the univariate analysis (HR: 1.21 ; 95\% CI: $0.87-1.68$, Cox $P=0.25$ ). However, the multivariate Cox regression model indicated a strong trend towards a worse OS of overweight + obese patients (HR: 1.49; 95\% CI: $1.00-2.23$, Cox $P=0.052$ ). Comparison of the group of obese patients with normal weight patients using this multivariate model demonstrated a significant worse OS of obese patients (HR: 1.81; 95\% CI: 1.13-2.92, Cox $P=0.015$; Figure 2).

Disease outcome: tamoxifen \pm aminoglutethimide according to BMI. With respect to DFS, no difference between overweight + obese patients and normal weight patients within the tamoxifen only arm and within the tamoxifen + aminoglutethimide arm could be observed (HR: 1.05; 95\% CI: $0.75-1.47$, Cox $P=0.79$ and HR: 1.17 ; 95\% CI: $0.84-1.63$, Cox $P=0.34$, respectively).

However, overweight + obese patients had a significant higher risk for distant metastases compared with normal weight patients within the tamoxifen + aminoglutethimide arm (HR: $1.67,95 \%$ CI: 1.04-2.68, Cox $P=0.03$; Figure 3), whereas there was no such difference within the tamoxifen arm (HR: 1.35, 95\% CI: 0.82-2.22, $\operatorname{Cox} P=0.24)$. Both results were confirmed using the multivariate Cox regression model. The higher risk for distant metastases of overweight patients treated with tamoxifen + aminoglutethimide translated into a worse OS compared with normal weight patients (HR: 1.47; 95\%CI: 0.92-2.36, Cox $P=0.11$ ). Using the multivariate Cox regression model, this trend turned out to be more distinct (HR: 1.73 ; 95\% CI: $0.96-3.13$, Cox $P=0.068$ ).

Regarding OS in the tamoxifen only arm, no difference between overweight + obese and normal weight patients was observed (HR: 0.99; 95\% CI: $0.63-1.57$, Cox $P=0.97$ ). HRs of multivariate Cox regression models are shown in Table 3.

When tamoxifen was compared with tamoxifen + aminoglutethimide in the normal weight group of patients, no difference with regard to DFS (HR: 0.93 ; 95\% CI: 0.63-1.36, Cox $P=0.70$ ) and OS (HR: 0.78 ; 95\% CI: $0.46-1.35$, Cox $P=0.38$ ) could be detected. Similarly, no difference in distant metastasis between the two treatment arms was observed in normal weight patients. 

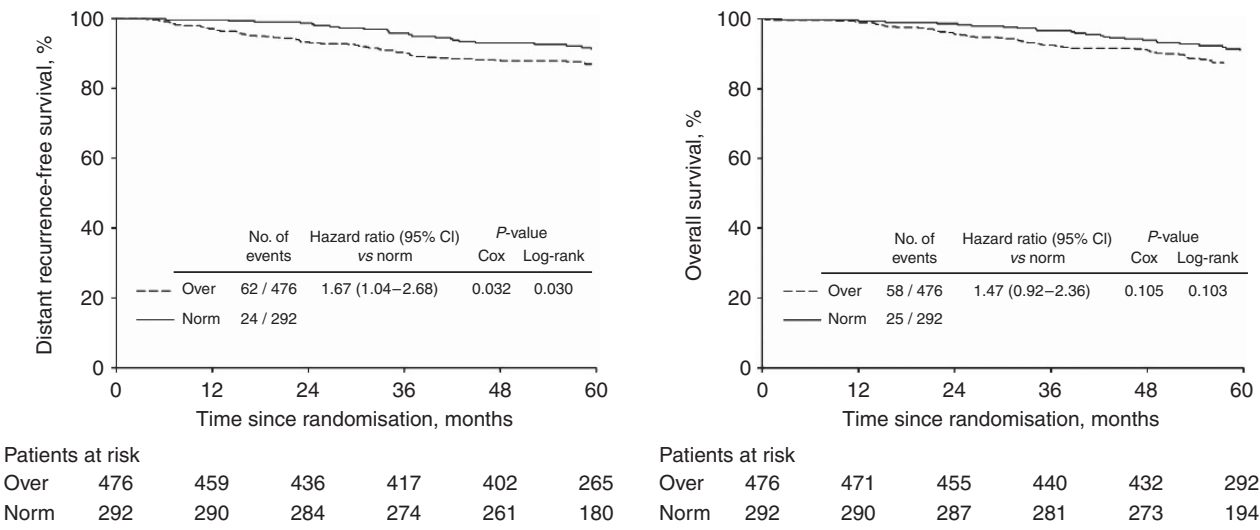

Figure 3. Distant recurrence-free survival and overall survival of overweight/obese vs normal weight patients treated with tamoxifen + aminoglutethimide.

\begin{tabular}{|c|c|c|c|c|c|c|}
\hline \multirow[b]{2}{*}{ DFS } & \multicolumn{2}{|c|}{ All } & \multicolumn{2}{|c|}{ Tamoxifen } & \multicolumn{2}{|c|}{ Tamoxifen + aminogluthtetimide } \\
\hline & HR & $95 \% \mathrm{Cl}$ & HR & $95 \% \mathrm{Cl}$ & $\mathrm{HR}$ & $95 \% \mathrm{Cl}$ \\
\hline Overweight + obese vs normal weight & 1.25 & $0.95-1.64$ & 1.27 & $0.86-1.87$ & 1.23 & $0.83-1.82$ \\
\hline Overweight vs normal weight & 1.15 & $0.85-1.55$ & 1.35 & $0.89-2.04$ & 0.99 & $0.64-1.53$ \\
\hline Obese vs normal weight & 1.45 & $1.03-2.02$ & 1.15 & $0.70-1.87$ & 1.78 & $1.12-2.83$ \\
\hline \multicolumn{7}{|l|}{ Distant recurrence-free survival } \\
\hline Overweight + obese vs normal weight & 1.62 & $1.09-2.42$ & 1.48 & $0.85-2.58$ & 1.81 & $1.02-3.22$ \\
\hline Overweight vs normal weight & 1.54 & $1.00-2.35$ & 1.58 & $0.88-2.86$ & 1.51 & $0.81-2.83$ \\
\hline Obese vs normal weight & 1.79 & $1.11-2.87$ & 1.31 & $0.66-2.60$ & 2.43 & $1.25-4.70$ \\
\hline \multicolumn{7}{|l|}{ Overall survival } \\
\hline Overweight + obese vs normal weight & 1.49 & $0.99-2.23$ & 1.29 & $0.74-2.24$ & 1.73 & $0.96-3.13$ \\
\hline Overweight vs normal weight & 1.34 & $0.87-2.07$ & 1.22 & $0.66-2.24$ & 1.48 & $0.78-2.80$ \\
\hline Obese vs normal weight & 1.81 & $1.12-2.91$ & 1.41 & $0.71-2.77$ & 2.28 & $1.16-4.51$ \\
\hline
\end{tabular}

Comparing tamoxifen to tamoxifen + aminoglutethimide in the group of overweight + obese patients, no difference regarding DFS (HR: $1.04 ; 95 \%$ CI: $0.79-1.37$, Cox $P=0.79$ ) and OS (HR: 1.17; $95 \%$ CI: $0.8-1.7$, Cox $P=0.42$ ) was detected. Similarly, no difference in distant recurrences between the tamoxifen only and tamoxifen + aminoglutethimide arm could be observed in this group of patients.

Safety and tolerability. As reported in the initial publication, more adverse events occurred in the combination arm. The numbers and proportions of most frequent side effects of overweight + obese $v s$ normal weight patients treated with tamoxifen and tamoxifen + aminoglutethimide, respectively, are shown in Table 4. No differences of side effects between normal and overweight + obese patients could be detected in the tamoxifen arm. This was also true for the combination arm. The occurrence of side effects in normal weight and overweight + obese patients treated with tamoxifen + aminoglutethimide was well balanced.

\section{DISCUSSION}

In this re-analysis of a large data set of postmenopausal women with hormone receptor-positive early breast cancer, we confirmed that BMI is an independent prognostic parameter. In general, overweight + obese patients had a higher risk for distant metastases and death compared with normal weight patients. This impact of BMI on disease outcome remained stable after adjustment for tumour stage, nodal stage, grade, ER, PR, and age.

Regarding DFS, we did not find a significant difference between overweight + obese patients and normal weight patients. This lack of impact of BMI on DFS in our analyses might be explained by two reasons. First, according to recent literature in this field, it seems that BMI mainly impacts on distant recurrences but not local recurrences, which were included in our definition of DFS (Majed et al, 2008; Ewertz et al, 2011). Second, Ewertz et al (2011) have suggested that the distinct impact of BMI on disease outcome appears only late in follow-up, that is, after a follow-up of 5 years. Therefore, the effect of BMI on distant recurrence as well as OS might be underestimated due to the censored follow-up in our analysis.

Recently, a re-analysis of the TEAM trial indicated that BMI impacts on the efficacy of tamoxifen after 2.75 years of treatment in postmenopausal patients with breast cancer (Seynaeve et al, 2011). These data are in striking contrast with re-analyses of the NSABP-14 trial and the ATAC trial reporting on a long-term follow-up. The ATAC trial clearly demonstrated that BMI had no influence on breast cancer recurrence in postmenopausal patients treated with tamoxifen (Sestak et al, 2010). The re-analysis of the NSABP B-14 trial can most likely give the answer whether BMI 


\begin{tabular}{|c|c|c|c|c|c|c|}
\hline & \multicolumn{2}{|c|}{ Tamoxifen } & \multicolumn{4}{|c|}{ Tamoxifen + aminoglutethimide } \\
\hline & $\begin{array}{c}\text { Normal } \\
\text { weight, } n \text { (\%) }\end{array}$ & $\begin{array}{c}\text { Overweight }+ \\
\text { obese, } \boldsymbol{n}(\%)\end{array}$ & $\boldsymbol{P}$-value & $\begin{array}{c}\text { Normal } \\
\text { weight, } n \text { (\%) }\end{array}$ & $\begin{array}{c}\text { Overweight }+ \\
\text { obese, } \boldsymbol{n}(\%)\end{array}$ & $\boldsymbol{P}$-value \\
\hline Pain & $47(17.9)$ & $84(17.6)$ & 0.920 & $49(16.8)$ & $83(17.4)$ & 0.844 \\
\hline Obstipation & $20(7.6)$ & $38(7.9)$ & 1.000 & $19(6.5)$ & $39(8.2)$ & 0.482 \\
\hline Headache & $41(15.6)$ & $76(15.9)$ & 1.000 & $42(14.4)$ & $66(13.9)$ & 0.832 \\
\hline Vertigo & 67 (25.5) & $118(24.7)$ & 0.859 & $77(26.4)$ & $115(24.2)$ & 0.494 \\
\hline Pruritus & 36 (13.7) & 65 (13.6) & 1.000 & 40 (13.7) & $67(14.1)$ & 0.915 \\
\hline Nausea & $27(10.3)$ & $37(7.7)$ & 0.274 & $29(9.9)$ & $69(14.5)$ & 0.075 \\
\hline Depression & 48 (18.3) & 89 (18.6) & 0.922 & $66(22.6)$ & $80(16.8)$ & 0.058 \\
\hline Cardial disorders & $7(2.7)$ & $19(4.0)$ & 0.410 & $13(4.5)$ & $20(4.2)$ & 0.857 \\
\hline Hot flush & $153(58.2)$ & $263(55.0)$ & 0.439 & $154(52.7)$ & $254(53.4)$ & 0.882 \\
\hline Bleeding & $6(2.3)$ & $7(1.5)$ & 0.560 & $4(1.4)$ & $9(1.9)$ & 0.775 \\
\hline
\end{tabular}

impacts on the efficacy of tamoxifen as it was a prospective randomised, placebo-controlled trial (Dignam et al, 2003). Data from this trial demonstrated that BMI does not influence the efficacy of tamoxifen with respect to breast cancer recurrence and mortality after breast cancer events (Dignam et al, 2003). In this analysis, we confirmed that BMI does not impact on the disease outcome in postmenopausal patients treated with tamoxifen, suggesting that tamoxifen is an effective endocrine treatment option in normal weight and overweight or obese patients.

In contrast, recent literature indicates that BMI significantly impacts on disease outcome in patients treated with non-steroidal aromatase inhibitors (Sestak et al, 2010, Pfeiler et al, 2011). Overweight patients treated with aromatase inhibitors have a higher risk for disease recurrence and death compared with normal weight patients. Therefore, it is in question whether BMI impacts on the combination of tamoxifen and an aromatase inhibitor.

Actually, combinations of an aromatase inhibitor and tamoxifen for endocrine treatment of postmenopausal patients are no longer considered. The ABCSG-06 trial as well as the ATAC trial demonstrated that the combination arm shows no superiority over the tamoxifen only arm, whereas side effects were obviously increased (Baum et al, 2002; Schmid et al, 2003). However, in the high-risk group of G3 tumours, the ABCSG-06 trial indicated a significant benefit for patients treated with the combination of tamoxifen and aminoglutethimide (Schmid et al, 2003).

Here, we analysed for the first time the impact of BMI on the efficacy of a combination of tamoxifen and an aromatase inhibitor. In contrast to the tamoxifen only arm, we observed differences in disease outcomes between predefined BMI categories in the combination treatment arm. In this analysis, we demonstrate that BMI significantly impacts on distant recurrences in patients treated with the combination tamoxifen + aminoglutethimide, but not in patients treated with tamoxifen only. The higher risk of distant recurrences of overweight patients in the combination arm translated into a trend towards a worse OS compared with normal weight patients. This is an potentially interesting observation as it mimics the worse outcome of overweight compared with normal weight patients treated with an aromatase inhibitor only in other studies (Sestak et al, 2010; Pfeiler et al, 2011). However, the biological reasons are mostly unclear. One can only speculate whether the observed effect would have been greater when a thirdgeneration aromatase inhibitor had been used.

As discussed, BMI impacts on disease outcome (de Azambuja et al, 2010; Protani et al, 2010; Ewertz et al, 2011). This may lead to a more intense therapy approach for overweight patients. However, increased BMI is also associated with a wide range of other diseases, which might diminish tolerance to certain therapies and increase treatment-related side effects (Berrington de Gonzalez et al, 2010; Cecchini et al, 2010). In our analysis, we did not find such confounding factors. We observed no differences in side effects according to BMI in patients treated with tamoxifen or tamoxifen + aminoglutethimide. This is of certain interest as an increase of several side effects, for example, vaginal bleeding or cardiac events, would have been expected in overweight and obese patients. However, as this observation is of retrospective nature not all important side effects (for instance arthralgia or libido) can be reported. Nonetheless, according to the literature and our data tamoxifen is an effective and safe endocrine treatment in normal and overweight patients with breast cancer.

In our re-analysis of the ABCSG-12 trial, we reported that only about one-third of premenopausal breast cancer patients were overweight or obese (Pfeiler et al, 2011). In contrast, in this collective of postmenopausal breast cancer patients, approximately two-third $(63 \%)$ were overweight $(42 \%)$ or obese $(21 \%)$. This underlines the particular importance of taking BMI into consideration for therapy decision and follow-up of postmenopausal women.

To summarise, we confirmed an independent prognostic value of BMI for adjuvant endocrine-treated postmenopausal breast cancer patients. Body mass index significantly impacts on the efficacy of tamoxifen + aminogluthetimide but not tamoxifen alone. With respect to side effects, tamoxifen seems to be well tolerated in normal weight as well as overweight and obese patients. The current investigation supports the hypothesis that BMI impacts on the efficacy of aromatase inhibitors but not tamoxifen. For upcoming studies using AI-based endocrine therapy, we recommend to factor in obesity and stratify data by BMI.

\section{ACKNOWLEDGEMENTS}

We thank our patients who contributed to this and other ABCSG trials; ABCSG investigators, study nurses, and data management associates, both in the individual trial centers and in the ABCSG center, who provided ongoing support; Hannes Fohler, and the statistical team. This work was supported by AstraZeneca (e.g., partly trial medication and financial support). 


\section{REFERENCES}

Baum M, Budzar AU, Cuzick J, Salmon RJ, Fourquet A, Asselain B (2002) Anastrozole alone or in combination with tamoxifen versus tamoxifen alone for adjuvant treatment of postmenopausal women with early breast cancer: first results of the ATAC randomised trial. Lancet 359: 2131-2139.

Berrington de Gonzalez A, Hartge P, Cerhan JR, Flint AJ, Hannan L, MacInnis RJ, Moore SC, Tobias GS, Anton-Culver H, Freeman LB, Beeson WL, Clipp SL (2010) Body-mass index and mortality among 1.46 million white adults. $N$ Engl J Med 363: 2211-2219.

Cecchini M, Sassi F, Lauer JA, Lee YY, Guajardo-Barron V, Chisholm D (2010) Tackling of unhealthy diets, physical inactivity, and obesity: health effects and cost-effectiveness. Lancet 376: 1775-1784.

de Azambuja E, McCaskill-Stevens W, Francis P, Quinaux E, Crown JP, Vicente M, Giuliani R, Nordenskjöld B, Gutiérez J, Andersson M, Vila MM, Jakesz R, Demol J, Dewar J, Santoro A, Lluch A, Olsen S, Gelber RD, Di Leo A, Piccart-Gebhart M (2010) The effect of body mass index on overall and disease-free survival in node-positive breast cancer patients treated with docetaxel and doxorubicin-containing adjuvant chemotherapy: the experience of the BIG 02-98 trial. Breast Cancer Res Treat 119: 145-153.

Després JP, Lemieux I (2006) Abdominal obesity and metabolic syndrome. Nature 444: 881-887.

Dignam JJ, Wieand K, Johnson KA, Fisher B, Xu L, Mamounas EP (2003) Obesity, tamoxifen use, and outcomes in women with estrogen receptorpositive early-stage breast cancer. J Natl Cancer Inst 95: 1467-1476.

Ewertz M, Jensen MB, Gunnarsdóttir KÁ, Højris I, Jakobsen EH, Nielsen D, Stenbygaard LE, Tange UB, Cold S (2011) Effect of obesity on prognosis after early-stage breast cancer. J Clin Oncol 29: 25-31.

Flegal KM, Carroll MD, Ogden CL, Curtin LR (2010) Prevalence and trends in obesity among US adults, 1999-2008. JAMA 303: 235-241.

Key TJ, Appleby PN, Reeves GK, Roddam A, Dorgan JF, Longcope C, Stanczyk FZ, Stephenson Jr HE, Falk RT, Miller R, Schatzkin A, Allen DS, Fentiman IS, Key TJ, Wang DY, Dowsett M, Thomas HV, Hankinson SE Toniolo P, Akhmedkhanov A, Koenig K, Shore RE, Zeleniuch-Jacquotte A, Berrino F, Muti P, Micheli A, Krogh V, Sieri S, Pala V, Venturelli E, Secreto G, Barrett-Connor E, Laughlin GA, Kabuto M, Akiba S, Stevens RG, Neriishi K, Land CE, Cauley JA, Kuller LH, Cummings SR, Helzlsouer KJ, Alberg AJ, Bush TL, Comstock GW, Gordon GB, Miller SR, Longcope C. Endogenous Hormones Breast Cancer Collaborative Group. (2003) Body mass index, serum sex hormones, and breast cancer risk in postmenopausal women. J Natl Cancer Inst 95: 1218-1226.

Lien EA, Anker G, Lonning PE, Solheim E, Ueland PM (1990) Decreased serum concentrations of tamoxifen and its metabolites induced by aminoglutethimide. Cancer Res 50: 5851-5857.
Longcope C, Baker R, Johnston CC (1986) Androgen and estrogen metabolism: relationship to obesity. Metabolism 35: 235-237.

Majed B, Moreau T, Senouci K, Salmon RJ, Fourquet A, Asselain B (2008) Is obesity an independent prognosis factor in woman breast cancer? Breast Cancer Res Treat 111: 329-342.

Parr CL, Batty GD, Lam TH, Barzi F, Fang X, Ho SC, Jee SH, AnsaryMoghaddam A, Jamrozik K, Ueshima H, Woodward M, Huxley RR (2010) Body-mass index and cancer mortality in the Asia-Pacific Cohort Studies Collaboration: pooled analyses of 424,519 participants. Lancet Oncol 11: 741-752.

Pfeiler G, Königsberg R, Fesl C, Mlineritsch B, Stoeger H, Singer CF, Pöstlberger S, Steger GG, Seifert M, Dubsky P, Taucher S, Samonigg H, Bjelic-Radisic V, Greil R, Marth C, Gnant M (2011) Impact of body mass index on the efficacy of endocrine therapy in premenopausal patients with breast cancer: an analysis of the prospective ABCSG-12 trial. J Clin Oncol 29: 2653-2659.

Protani M, Coory M, Martin JH (2010) Effect of obesity on survival of women with breast cancer: systematic review and meta-analysis. Breast Cancer Res Treat 123: 627-635.

Renehan AG, Tyson M, Egger M, Heller RF, Zwahlen M (2008) Body-mass index and incidence of cancer: a systematic review and meta-analysis of prospective observational studies. Lancet 371: 569-578.

Schmid M, Jakesz R, Samonigg H, Kubista E, Gnant M, Menzel C, Seifert M, Haider K, Taucher S, Mlineritsch B, Steindorfer P, Kwasny W (2003) Randomized trial of tamoxifen versus tamoxifen plus aminoglutethimide as adjuvant treatment in postmenopausal breast cancer patients with hormone receptor-positive disease: Austrian breast and colorectal cancer study group trial 6. J Clin Oncol 21: 984-990.

Sestak I, Distler W, Forbes JF, Dowsett M, Howell A, Cuzick J (2010) Effect of body mass index on recurrences in tamoxifen and anastrozole treated women: an exploratory analysis from the ATAC trial. J Clin Oncol 28: 3411-3415.

Seynaeve C, Hille E, Hasenburg A, Rea D, Markopoulos C, Hozumi Y, Putter H, Nortier H, van Nes J, Dirix L, van de Velde. C. The impact of body mass index (BMI) on the efficacy of adjuvant endocrine therapy in postmenopausal hormone sensitive breast cancer (BC) patients; exploratory analysis from the TEAM study. Cancer Res (2011) 70: S2-S3. WHO (1995) Physical status: the use and interpretation of anthropometry. Report of a WHO Expert Committee. WHO Technical Report Series 854. World Health Organization: Geneva.

This work is published under the standard license to publish agreement. After 12 months the work will become freely available and the license terms will switch to a Creative Commons AttributionNonCommercial-Share Alike 3.0 Unported License. 